\title{
A Cooperativa Fernheim dos imigrantes menonitas de Filadélfia, Paraguai
}

\author{
The Fernheim Cooperative of the mennonite immigrants of Philadelphia, Paraguay
}

\section{La Cooperativa Fernheim de los inmigrantes menonitas de Filadelfia, Paraguay}

\author{
Odemir Coelho da Costa ${ }^{1}$ \\ Sandino Hoff ${ }^{1}$
}

Recebido em: 27/03/2018. Revisado e aprovado em: 04/06/2018. Aceito em: 24/08/2018.

DOI: http://dx.doi.org/10.20435/inter.v21i1.1901

\begin{abstract}
Resumo: O presente artigo tem por objetivo geral analisar a mediação exercida pela Cooperativa Fernheim, de Filadélfia, Paraguai, entre o produtor, a comercialização e a industrialização do produto. A Cooperativa desempenha um importante papel para o desenvolvimento regional do Chaco Central, não só a partir da industrialização de produtos e comercialização, mas também, com as inovações implantadas para o manuseio da água. A problematização do objeto de estudo orienta-se para os seguintes questionamentos: quais as ações efetuadas pela Cooperativa Fernheim que propiciam o desenvolvimento econômico e social dos cooperados? Qual a importância da Cooperativa para a comercialização e a industrialização dos produtos? Como é efetuada a aplicação financeira da Cooperativa e para quais setores são direcionados os créditos dos cooperados? Quais as inovações tecnológicas desenvolvidas pela Cooperativa para o tratamento da água salobra que auxiliam no desenvolvimento do município? Os questionamentos são sintetizados nos objetivos específicos: verificar as atividades produtivas que a Cooperativa oferece ao produtor rural, enquanto apoio ao financiamento, à compra e industrialização dos produtos vegetais e animais; e analisar as inovações tecnológicas que possibilitaram o abastecimento e o consumo da água, originalmente salobra. A sistematização dos dados foi realizada pela Análise de Conteúdo de Bardin. Como aporte teórico, adotamos a teoria da história que investigou os pormenores das ações econômicas e sociais realizadas pela Cooperativa, consideradas como manifestações singulares do movimento geral do capital.
\end{abstract}

Palavras-chave: crescimento; desenvolvimento social; cooperativismo; trabalho familiar.

Abstract: This article aims to analyze the mediation exercised by the Fernheim Cooperative of Philadelphia, Paraguay, between the producer, the commercialization and the industrialization of the product. The Cooperative plays an important role for the regional development of the Central Chaco, not only from the industrialization of products and commercialization, but also with the innovations implanted for the handling of water. The problematization of the object of study is oriented to the following questions: What are the actions carried out by the Fernheim Cooperative that promote the economic and social development of the cooperative? What is the importance of the Cooperative for the commercialization and industrialization of products? How is the financial application of the Cooperative effected and to which sectors are the credits of the cooperatives directed? What are the technological innovations developed by the Cooperative for the treatment of brackish water that help in the development of the municipality? The questions are summed up in the specific objectives: to verify the productive activities that the Cooperative offers to the rural producer, as support to the financing, purchase and industrialization of the vegetal and animal products; and analyze the technological innovations that made possible the supply and consumption of water, originally brackish. The data systematization was performed by Bardin Content Analysis. As a theoretical contribution, we adopted the theory of history that investigated the details of the economic and social actions carried out by the Cooperative, considered as singular manifestations of the general movement of capital.

Keywords: growth; social development; cooperativism; family work.

Resumen: El presente artículo tiene por objetivo general analizar la mediación ejercida por la Cooperativa Fernheim, de Filadelfia, Paraguay, entre el productor, la comercialización y la industrialización del producto. La Cooperativa desempeña un importante papel para el desarrollo regional del Chaco Central, no sólo a partir de la industrialización de productos y comercialización, sino también, con las innovaciones implantadas para el manejo del agua. La problematización del objeto de estudio se orienta a los siguientes cuestionamientos:

\footnotetext{
${ }^{1}$ Universidade Anhanguera-Uniderp, Campo Grande, Mato Grosso do Sul, Brasil.
} 
¿Cuáles son las acciones efectuadas por la Cooperativa Fernheim que propician el desarrollo económico y social de los cooperados? ¿Cuál es la importancia de la Cooperativa para la comercialización y la industrialización de los productos? ¿Cómo se efectúa la aplicación financiera de la Cooperativa y para qué sectores se dirigen los créditos de los cooperados? ¿Cuáles son las innovaciones tecnológicas desarrolladas por la Cooperativa para el tratamiento del agua salada que auxilian en el desarrollo del municipio? Los cuestionamientos se sintetizan en los objetivos específicos: verificar las actividades productivas que la Cooperativa ofrece al productor rural, en cuanto apoyo a la financiación, a la compra e industrialización de los productos vegetales y animales; y analizar las innovaciones tecnológicas que posibilitar el abastecimiento y el consumo del agua, originalmente salobre. La sistematización de los datos fue realizada por el Análisis de Contenido de Bardin. Como aporte teórico, adoptamos la teoría de la historia que investigó los detalles de las acciones económicas y sociales realizadas por la Cooperativa, consideradas como manifestaciones singulares del movimiento general del capital.

Palabras clave: crecimiento; desarrollo social; cooperativismo; trabajo familiar.

\section{INTRODUÇÃO}

A Cooperativa Fernheim, localizada na Colônia Fernheim, município de Filadélfia no Chaco Paraguaio, uma instituição criada pelos habitantes de religião menonita, foi o objeto de estudo analisado neste artigo. Exercendo a função de produzir, comercializar e industrializar as mercadorias produzidas pelos agricultores do município, os habitantes da colônia criaram esse instrumento econômico com a finalidade de sanar as dificuldades de sobrevivência do grupo.

Os menonitas migraram da Alemanha e dos Países Baixos para a Rússia, a convite de Catarina, a Grande, na segunda metade do século XVIII. Com a socialização da União Soviética em 1917, eles não se encontraram mais nos seus princípios tradicionais de cultura e de religião. Em movimento coletivo, saíram da União Soviética e se espalharam por muitos países. Em 1931, um grupo deles chegou ao Chaco Paraguaio e fundou a Colônia Fernheim. Anos após, os habitantes criaram a Cooperativa, amparados na Lei 514/21 (PARAGUAI, 1921).

Especificamente, obtiveram do governo uma série de garantias, como liberdade religiosa, permissão para utilizar o idioma alemão e para organizar a educação e a cultura. Reyes (2009, p. 50) destacou que, depois de instalados em Filadélfia, os menonitas "começaram a se organizar de acordo com a atitude que estava já internalizada pela experiência vivida na Rússia, [...] cultivando valores de solidariedade, ajuda mútua e cooperação". Permeados por tais valores, construíram instalações, organizando um centro administrativo e uma loja na qual eram negociados os produtos da Colônia, especialmente hortaliças, frutos e ovos de granja. Em trabalho coletivo, levantaram casas de moradia e de abrigo às ferramentas de trabalho, aos animais de arado e ao gado leiteiro.

O objetivo da investigação foi examinar as atividades produtivas da Cooperativa, que exerceu a mediação nas operações de financiamento, de compra, industrialização e exportação dos produtos vegetais e animais, no pagamento de impostos sobre a terra e na construção de estradas. Três ideias básicas decorreram do objetivo: a despeito de que muitos considerem que as atividades da cooperativa na sociedade produtora de Fernheim enquadram-se em formas de reprodução simples da comunidade ou até em resistência ao capitalismo, estabeleceu-se, neste estudo, que o desenvolvimento proporcionado pela cooperativa foi uma forma de produção peculiar, específica, que manifestou no seu interior as leis gerais da sociedade capitalista; verificou-se que à cooperativa competia o crescimento econômico, enquanto os valores sociais, culturais e religiosos faziam parte dos cuidados da Associação Civil; investigou-se a mediação exercida pela cooperativa no seio da sociedade civil de Fernheim como uma tentativa de efetuar um desenvolvimento sustentável possível. 
Considerou-se pertinente destacar que são escassos os estudos e as pesquisas a respeito da Cooperativa Fernheim.

\section{DESENVOLVIMENTO}

\subsection{Material e métodos}

A coleta de dados da pesquisa foi efetuada em depoimentos colhidos por ocasião das visitas e observações in loco na cidade e na Cooperativa Fernheim; na aplicação de questionários, vertidos para a língua alemã, junto aos associados; em documentos disponíveis na Cooperativa e na Associação; em relatórios divulgados sobre a organização, o funcionamento, a manipulação financeira e as estratégias adotadas para o desenvolvimento regional e a sustentabilidade ambiental; no Estatuto Social da Cooperativa e na Lei de Amparo à Cooperativa; e na legislação pertinente.

A investigação efetuada levou em consideração, ainda, registros fotográficos de Filadélfia e levantamento bibliográfico de pesquisas publicadas. Na visita à cidade, realizada em dezembro de 2016, observou-se a vida dos habitantes e colheram-se informações sobre a Cooperativa e a instituição a ela ligada, denominada Associação Civil. Para o levantamento dos dados, contou-se com pessoas da Colônia Fernheim que possibilitaram as entrevistas, a aplicação dos questionários, os depoimentos e o acesso aos documentos. Neste primeiro encontro, os moradores e os dirigentes prestaram informações que oportunizaram o conhecimento, mesmo superficial, do trabalho da comunidade menonita. Inicialmente, foi feito contato com a responsável pelo setor de documentação, que se demonstrou receptiva à pesquisa, apresentando o setor que ela dirigia, com todas as suas especificidades, e se colocando à disposição para esclarecimentos necessários, especificamente em relação à história da Cooperativa Fernheim e seu funcionamento. Faz-se necessário destacar ainda que a pesquisa teve a aprovação do Comitê de Ética, conforme o registro 66707717.2.0000.5161, de 27/06/2017.

Na segunda visita, houve o preenchimento dos questionários pelas autoridades do município e da Cooperativa, associados encarregados de seções da Cooperativa e produtores. Os questionários foram aplicados na Cooperativa Fernheim em 30 de junho de 2017, em horário previamente combinado entre o pesquisador, os cooperados entrevistados e os outros entrevistados. Da mesma forma, o questionário foi respondido por outras 10 pessoas, incluindo chefe, gerentes, trabalhadores urbanos, professora, agricultores e funcionários, estando constituído com 16 questões acerca da organização da Cooperativa Fernheim e da vida do grupo menonita. As questões apresentaram, também, linhas em branco para que os respondentes pudessem expressar-se livremente. Foram feitos registros de observações realizadas em vários setores.

O conteúdo dos documentos e dos questionários foi sistematizado pela técnica da análise temática, ligada à Análise de Conteúdo, desenvolvida por Bardin (2004). Os dados coletados foram sistematizados a partir das temáticas levantadas: o papel desempenhado pela Cooperativa Fernheim junto ao produtor rural e a comercialização dos produtos; a compra e venda dos produtos agrícolas; a distribuição da renda dos cooperados; a exportação dos produtos agrícolas e a industrialização; a relação da Cooperativa, administrando a infraestrutura, com a Associação Civil, dirigida à superestrutura - temáticas organizadas a partir dos discursos, das entrevistas e dos documentos, que foram submetidos aos procedimentos analíticos. O procedimento seguiu com o tratamento dos resultados, as inferências e as interpretações. O mapa abaixo mostra a localização da região pesquisada, mais precisamente, a cidade de Filadélfia. 
Figura 1 - Município de Filadélfia localizado na região ocidental do Chaco Paraguaio

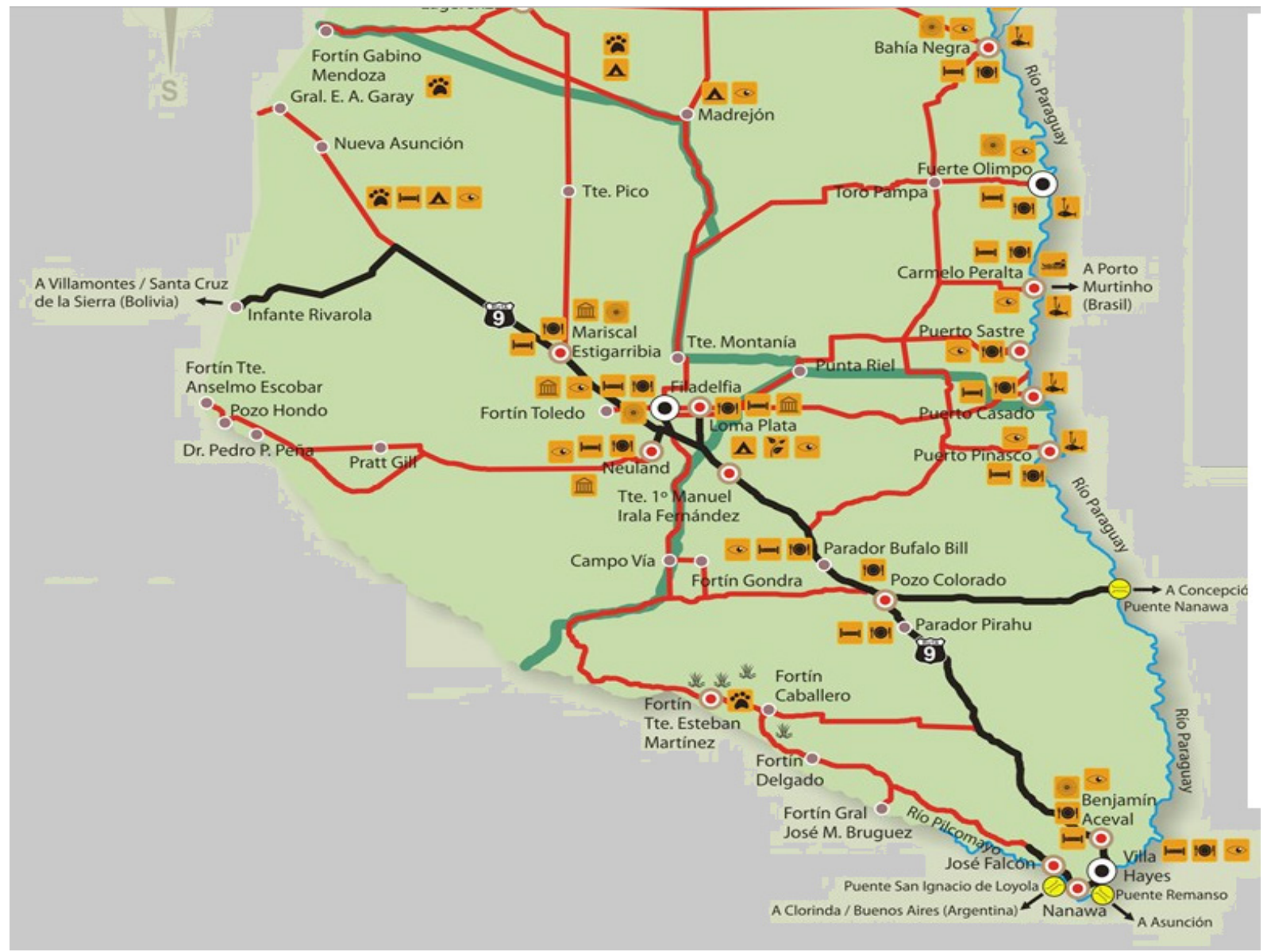

Fonte: Disponível em: https://vivendointercambio.files.wordpress.com/2012/04/m_chaco.jpg. Acesso em: 13 jan. 2020.

O município de Filadélfia tem um clima semiárido, com média de temperatura de 24 graus Celsius, chegando a 45 graus Celsius no verão (LARROZA CRISTALDO, 2002, p. 17).

\section{RESULTADOS E DISCUSSÃO}

\subsection{Os primeiros tempos da colônia}

Dados levantados no Setor de Informação e Documentação da Cooperativa revelaram que a ocupação no Chaco Paraguaio foi realizada com a aprovação do governo e a garantia de que os menonitas pudessem preservar sua cultura e cultuar seus valores religiosos e suas tradições.

Do lado paraguaio, o governo buscou encontrar novos grupos de pessoas, não indígenas, que ocupassem a região e auxiliassem no desenvolvimento do país, por meio de atividades lucrativas e que protegessem o território nacional. As características do clima e do solo, com escassas chuvas, carência de minerais no solo e poucos recursos à disposição, haviam estigmatizado a região, tornando-a complexa para fins de colonização. O governo guarani, para que se concretizasse a ocupação e o uso das terras, concedeu-Ihes a sanção por meio da Lei 514/21 (PARAGUAI, 1921), dando liberdade religiosa, cultural e educacional ao grupo.

Os menonitas partiram das colônias russas e se instalaram em território paraguaio em 1931, somando um total de 1.579 pessoas. Os novos habitantes estabeleceram-se no Chaco Central (Figura 2), uma região semiárida, com poucas vegetações. Conforme relato de um dos 
depoentes, eles enfrentaram situações precárias de vida: "Não havia hospitais, o clima era seco e a água escassa". No depoimento, um dos gerentes participantes informou: "Temos registros daquela época em fotos e documentos. Aqui os guardamos: da primeira escola na aldeia em 1934, as primeiras instalações. Quando os menonitas chegaram não tinha nada, deixaram tudo para trás na Rússia".

Figura 2 - Regiões fisiográficas do Chaco e Chaco Central

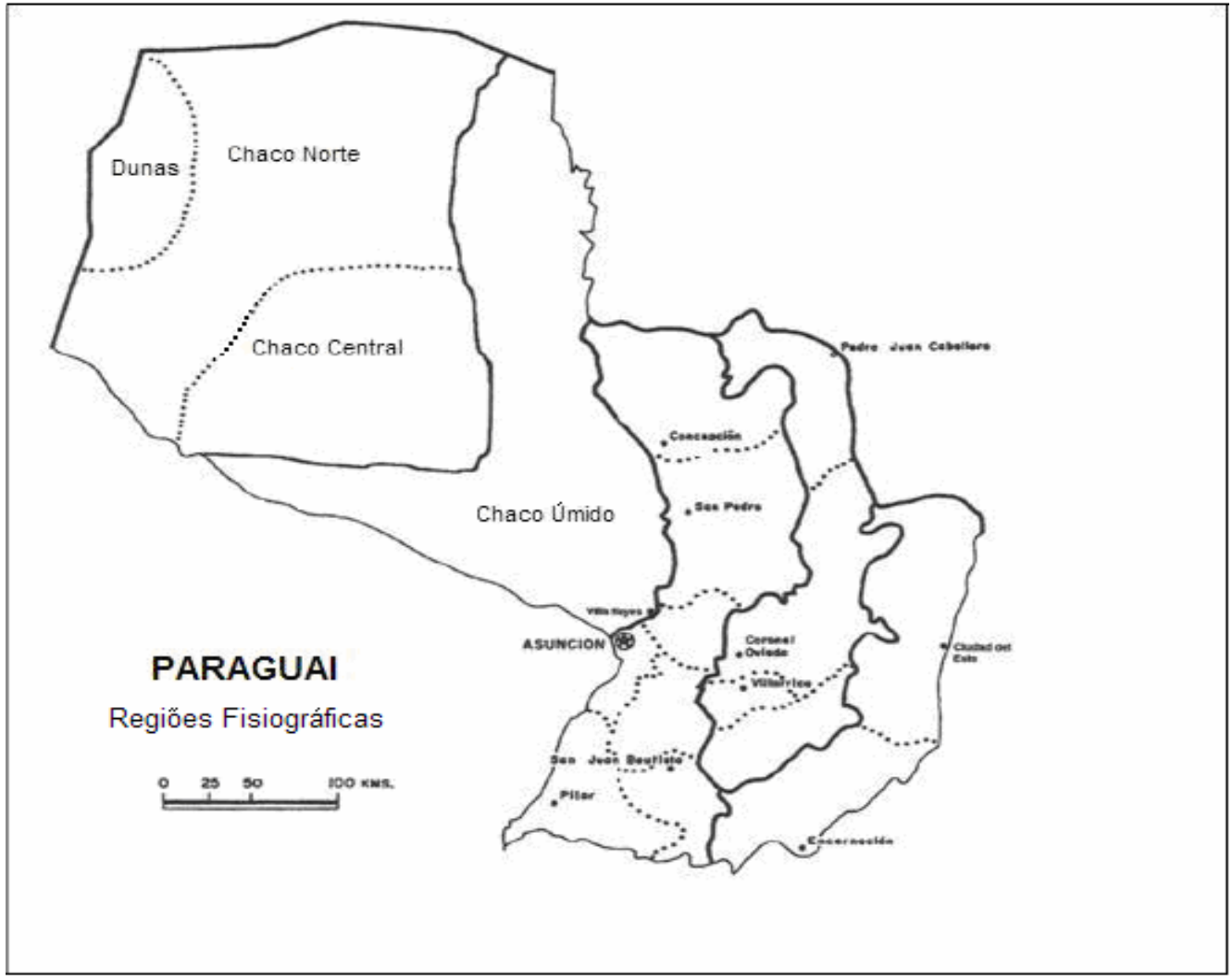

Fonte: Warkentin (1987).

A história inicial da Colônia Fernheim está fixa na memória de seus habitantes e os depoentes a relembram em pormenores os eventos, indicando construções visíveis e apontando as peças no museu: "Nossos antepassados contam a história e também têm os registros dos museus, de fotos e tudo. Também nossa história é contada no site da Cooperativa. Agora a Cooperativa é bem estruturada, todos os colaboradores trabalham e colaboram para o desenvolvimento da Cooperativa e da Associação".

Geralmente, a sociedade destrói os apoios da memória e substitui a lembrança pela história oficial. Na opinião da socióloga Marilena Chauí, "As lembranças pessoais e grupais são invadidas por outra 'história', por outra memória que rouba das primeiras o sentido, a transparência e a verdade", em que a vitória do vencedor, geralmente, "pisoteia a tradição dos vencidos" (CHAUÍ, 1979, p. 18). As recordações dos depoentes, entretanto, foram apreendidas como reflexões e sentimentos correspondentes à verdade dos fatos. Isso porque buscaram a confirmação do que se passou com seus antepassados e confrontaram a história com a situação atual, sem celebrações, apenas como cumprimento dos princípios e valores herdados dos antigos. 
O depoimento do responsável pela instituição fez questão de acentuar os valores que os menonitas tinham trazido da Rússia e que faziam parte de suas vidas: "Todos os valores religiosos, educacionais, sociais, ligados à laboriosidade do menonita, à cooperação e à organização". Os princípios ético-sociais assumidos resultaram na criação de "um centro administrativo na cidade de Filadélfia, com a organização de onze aldeias, contabilizando um total de 145 famílias". A cooperação e a organização foram responsáveis pela "preservação dos valores que permanecem até hoje. Desde criança, aprendemos na escola sobre cooperativismo, sobre a religião e, principalmente, sobre o trabalho" (Responsável pelas instituições).

Os valores do grupo foram assumidos, também, pelos moradores que foram trabalhar na região: "Uma grande quantidade de paraguaios, indígenas e latinos, convertidos ou não, são considerados na sociedade da colônia. No entanto, prevalece a hegemonia dos emigrantes alemães étnicos" (MÜHLAN, 2014, p. 34).

Um funcionário de órgão público do governo paraguaio fez lembrar que os menonitas, durante o período da imigração no Paraguai, "tinham apoio do Comitê Central Menonita, que é um órgão internacional". Ao criar a Cooperativa Fernheim, os imigrantes também tiveram "auxílio do Comitê Menonita dos Estados Unidos, cujo montante em dinheiro possibilitou a compra de um território de 135 mil hectares num local chamado campo do Trébol" (TORRACA, 2006).

O território foi todo organizado em lotes de terra, posteriormente dividido entre as famílias de imigrantes. O estilo de vida comunitário adotado favoreceu a evolução das primeiras atividades comerciais, o que fortaleceu o desenvolvimento da Colônia e, consequentemente, a criação da Cooperativa Fernheim. Foi nesse cenário que se inicializaram a cultura de diversos plantios. Inicialmente, se produziam amendoim, algodão e mantimentos. (Depoimento de um agricultor).

Os primeiros meses de vida foram dedicados à construção de abrigos aos imigrantes: casas, prédios, centro administrativo e "toda a estrutura necessária para manter as pessoas aqui. Como a condição de vida era difícil, nosso grupo foi se estabelecendo aos poucos. Então, foi criada a Colônia Fernheim e depois a Cooperativa Fernheim. A escola e a igreja foram às primeiras instituições criadas" (Responsável pela Cooperativa Fernheim).

Um dos depoentes, pecuarista, ofereceu mais informações:

Tinha a capacidade de sobreviver em condições desfavoráveis. Faltava água, então fizemos os "tajamares". Não tínhamos moeda para circular em nossas vendas, então criamos uma moeda simbólica para compras e vendas de produtos. É uma moeda que circula somente na Colônia Fernheim.

Outro depoente frisou fatos marcantes ligados ao modo de viver dos menonitas:

A construção de escolas e da igreja. Em 1932, a construção de nosso primeiro hospital, que inclusive atendia soldados durante a guerra, além de servir de escritório dos nossos primeiros administradores. Em 1936, tivemos a construção da Escola, em Filadélfia, ponto estratégico para outros locais.

À questão sobre a produção do campo e a geração de renda, os depoentes informaram que a economia local atual gira em torno da pecuária, especialmente de gado de corte e leiteiro. A organização do trabalho fica a cargo das famílias em suas propriedades, ressalvando-se que o trabalho faz parte dos valores dos menonitas. Quando se verifica a questão da propriedade do agricultor, pode-se pensar erroneamente e atribuir à comunidade um modo de produzir pré- 
-capitalista. A norma é: "o proprietário, que adquiriu a terra, não pode vendê-la sem autorização da Associação Civil", conforme esclareceram dois produtores do campo. A norma não está a indicar uma reserva à propriedade privada ou uma resistência ao capitalismo.

O trabalho comum não significa recuar à forma comunitária do limiar da história dos povos. O trabalho familiar e o comunitário, que produzem as próprias necessidades primárias, são distribuídos entre os membros, porque a função da família é fazer sua própria divisão do trabaIho. O trabalho de cada indivíduo opera como dispêndio de forças "medido pelo tempo de sua duração e se manifesta, aqui, simplesmente, em trabalhos socialmente determinados" (MARX, 1980 , p. 85-6). Uma parte do produto do trabalho é consumida pelos membros da família ou da comunidade; logo, deve ser distribuída entre eles, conforme é determinado pelo seu tempo de trabalho. A outra parte, porém, é utilizada como meio de produção. A Cooperativa Fernheim faz a mediação, intervindo no processo do financiamento, da comercialização e do consumo final do produto social realizado pelo trabalho familiar ou comunitário, e sua intervenção imprime o caráter capitalista a essa forma de trabalho. A cooperativa representa o mercado para as famílias.

\subsection{O desenvolvimento social e sustentável da cooperativa: entre o passado e o presente}

A Cooperativa Fernheim é amparada pela Lei de Cooperativas n. 438/94, Paraguai, de 21 de outubro de 1994, que determinou as normas gerais de seu funcionamento. Entretanto já está em funcionamento desde sua criação, em 1931. Iniciou suas atividades no armazém de consumo, na oficina e na caixa, a partir da qual se administravam as contas dos sócios. (Figura 3).

Uma das funcionárias da empresa, Agate Harder, listou algumas instituições de serviços significativos para a população: "A Cooperativa já tem supermercado, veterinária, loja de ferragens, frigorífico, laticínio, curtume. Na parte social, a Cooperativa mantém hospital, seis escolas que ofertam o ensino primário e secundário e, ainda, tem o Lar dos Idosos". O resumo apresentado pela funcionária revelou a ligação da cooperativa com o desenvolvimento social e cultural da colônia.

Em termos de crescimento econômico, a cooperativa, em primeiro momento, instalou uma loja destinada a vender os excedentes e a adquirir produtos. A iniciativa permitiu ao associado ter um saldo credor ou devedor, e à cooperativa, realizar vendas e compras e juntar um capital².

\footnotetext{
${ }^{2}$ Informações obtidas no Setor de Informação e Documentação da Cooperativa Fernheim, em visita no dia 10 de setembro de 2017
} 
Figura 3 - A sede da Sociedade Cooperativa Colonizadora Fernheim

\section{1}

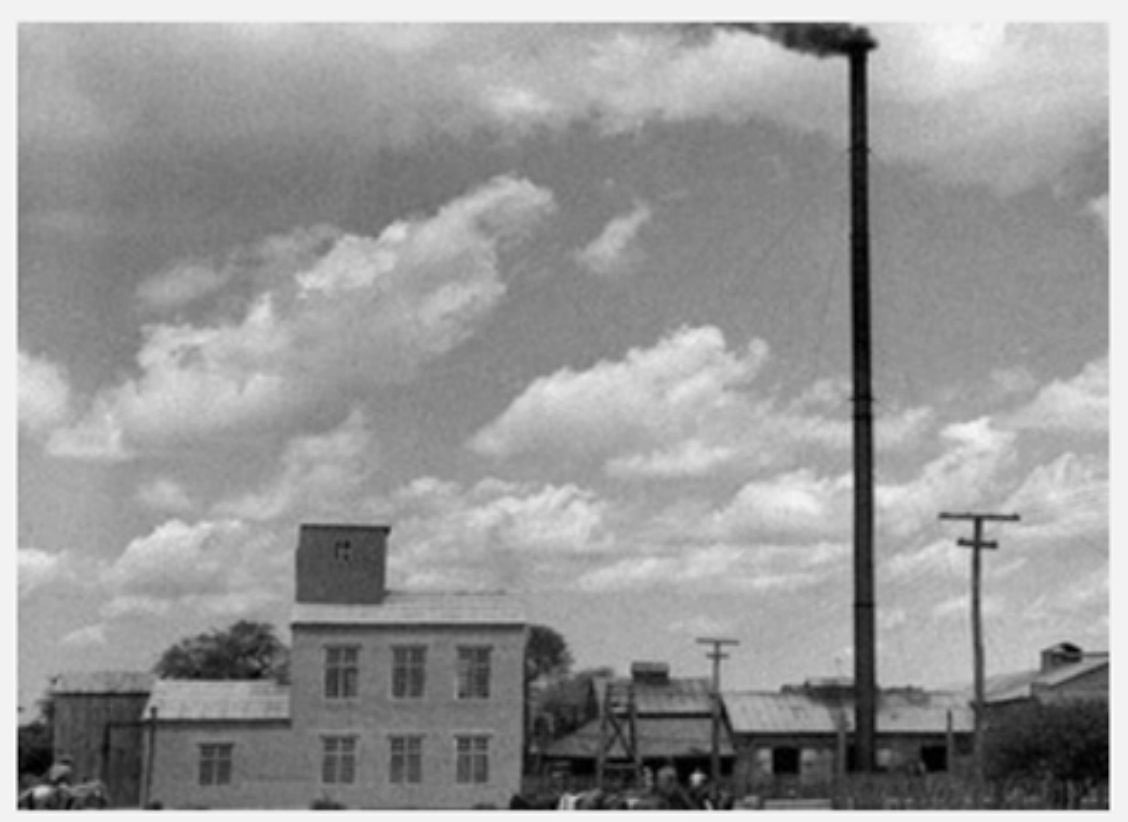

Fonte: Cooperativa Fernheim (2017).

Transcorreram meses difíceis para os menonitas no Chaco Central. Esse período de situação penosa foi lembrado por todos os depoentes. Afirmaram, porém, que sempre "priorizaram o pacifismo", o que não deixou que a Colônia Fernheim oferecesse ao exército paraguaio amparo hospitalar e mantimentos na época da Guerra do Chaco (1932 a 1935), entre a Bolívia e o Paraguai, conforme argumentou a gerente de um dos setores. A guerra, de um lado, produziu problemas para os assentados e, de outro, oportunizou uma pequena geração de renda, em época de lutas pela sobrevivência do grupo. Os produtores, por meio da cooperativa, forneceram ao exército paraguaio alimentos da terra e produtos oriundos das granjas, como ovos e carne. Além disso, tem-se a informação de um diretor de que ferragens e chapas, resultantes da guerra, foram reaproveitadas pelas oficinas menonitas.

Na década de 1950, a Cooperativa Fernheim conseguiu um empréstimo de US\$ 76 mil com o apoio do Comitê Central Menonita dos Estados Unidos. Uma gerente do setor da Cooperativa completou a informação: "Tratava-se de um empréstimo, não de doação". Tinha por finalidade financiar as instalações para a industrialização de produtos agropecuários e para a aquisição de equipamentos e máquinas utilizados no processamento de leite. O empréstimo foi abatido nos 13 anos seguintes.

Em 1966, a Cooperativa Fernheim e as demais cooperativas do Chaco Central solicitaram e obtiveram um empréstimo de um milhão de dólares dos bancos dos Estados Unidos, visando à mecanização da agricultura, com o prazo de 20 anos para sua amortização. O governo paraguaio aprovou a transação (Setor de Informação e de Documentação). O empréstimo garantiu a industrialização dos produtos primários, especialmente a carne e o leite, bem como a comercialização das mercadorias no mercado nacional e internacional. Ao mesmo tempo, possibilitou a implantação de tecnologia de ponta no processamento de carne, leite e produtos derivados, a melhoria dos pastos e a assistência de profissionais americanos na mecanização da lavoura. 
Na década de 1970, houve um grande desenvolvimento da cooperativa, visível por sua nova estrutura. O gerente e os documentos consultados demarcaram a seguinte estrutura: Seção Mercado de Produtos Agrícolas, Seção Comercial, Mercado de Produtos de Gado, Contabilidade, Hotel Flórida, Planta Industrial, Farmácia, Livraria, Planta Leiteira, Chácara Experimental, Educação Cooperativista, Assistência Técnica Fernheim e Frigorífico ${ }^{3}$.

A instituição comprou 10 mil hectares de terras e instalou as câmaras frigoríficas para a comercialização da carne bovina, com capacidade para abater 150 animais por dia ${ }^{4}$, passando a desenvolver consideravelmente o setor industrial, especialmente a partir da construção do Frigorífico Frigochaco, pertencente à cooperativa. Houve um elevado investimento em tecnologia na carne de bovinos, em sementes e no plantio de grãos. Mercadorias, com financiamentos bancários mediados pela Cooperativa, foram produzidas para atendimento do mercado interno e externo: manteiga, doce de leite, iogurte, leite pasteurizado e queijo ${ }^{5}$.

A operacionalização da cooperativa pode ser resumida da seguinte forma: além de pagar pelos produtos comercializados, distribui $10 \%$ da renda aos associados. Essa operação é comum a todas as cooperativas agrícolas que se conhecem. Quanto à organização, há a Assembleia Geral dos sócios e um Conselho Administrativo, composto por seis membros, incluindo o presidente, responsáveis por contratar gerentes de diferentes áreas de atuação e por eleger um Conselho de Vigilância, composto de três pessoas. Os mandatos têm a duração de três anos e o presidente pode ser reeleito pelos associados apenas uma única vez. Os demais cargos não têm nenhuma limitação de tempo, podendo os membros ser reeleitos indefinidamente. A divisão do trabalho em grande escala fez-se necessária.

Com a extensão de suas atividades, a cooperativa conseguiu alcançar êxito financeiro e social, que se resumiu em melhorar a genética de bovinos e em modernizar as práticas de investimentos em máquinas de produção e de industrialização. Racionalizou a oferta de serviços internos, reservou capital para o investimento em tecnologias de última geração e aumentou a exportação.

Além da terra, do gado e do leite, o couro também contém valor de exportação. Quanto ao gerir a parte financeira: "É de responsabilidade do Setor de Contabilidade, que efetua a abertura e a manutenção de contas-correntes. Os sócios utilizam os créditos na agricultura, na produção leiteira ou na agropecuária" 6 . Os associados devem residir no Chaco Paraguaio.

Nos anos 1980, as colônias Menno, Fernheim e Neuland receberam um financiamento de 7,2 milhões de dólares do Banco Interamericano do Desenvolvimento (BID), destinado ao desenvolvimento da produção leiteira nas fazendas, que favoreceu a todos os cooperados, num total de dois mil sócios que se dedicam à agricultura e à pecuária.

A Cooperativa Fernheim, com o empréstimo, investiu capital no setor industrial, no porte genético, produção, energia e na especialização do trabalhador. Empregou capital nos sistemas sociais: comunicação, saúde, educação e assistência social, com a finalidade de diminuir desi-

\footnotetext{
${ }^{3}$ Informações obtidas no Setor de Informação e Documentação da Cooperativa Fernheim, em visita no dia 10 de setembro de 2017.

${ }^{4}$ Disponível em: https://www.fernheim.com.py/en/. Acesso em: 10 julho. 2017.

${ }^{5}$ Informações obtidas no Setor de Informação e Documentação da Cooperativa Fernheim, em visita no dia 10 de setembro de 2017.

${ }^{6}$ Idem.
}

INTERAÇÕES, Campo Grande, MS, v. 21, n. 1, p. 51-66, jan./mar. 2020 
gualdades. Empregou capital para a fertilidade do solo e a captação de água ${ }^{7}$. O discurso dos dirigentes da cooperativa referiu-se ao fato de que, com os investimentos, não houve apenas "desenvolvimento na localidade e crescimento econômico, mas também, promoção do desenvolvimento sustentável".

A informação colhida em documentos evidencia a ligação mantida pela cooperativa com o sistema multifuncional de cooperativas paraguaias. Foi possível, dessa maneira, promover o processamento de produtos, transporte, crédito, industrialização e exportação das mercadorias ${ }^{8}$.

Segundo o Informe de Calificación, em 2017, a Cooperativa Fernheim "realiza atividades produtivas, fornece serviços e atua como uma cooperativa de poupança e crédito, o que implica uma alta diversificação por linha de negócios". As atividades produtivas representam 78\% dos negócios da cooperativa, exportando para os mercados da Rússia, Chile, Israel e Brasil (FELLER RATE, 2017). Os dados deste boletim destacaram que a principal atividade da instituição correspondeu a negócios liderados pela comercialização de carne bovina, por meio do Frigorífico Frigochaco (Figura 4).

Dirigentes da cooperativa afiançaram que a indústria paraguaia de abate de carne exporta seus produtos para diferentes mercados, competindo diretamente com países exportadores, como Brasil, Argentina e Uruguai. O gado processado provém da compra de membros cooperativos, agricultores terceirizados e da própria Cooperativa, que detém e administra cinco fazendas (FELLER. RATE, 2017).

Figura 4 - Boletim de exportação anual de carne bovina

Cooperativa Fernheim

Exportação de carne bovina anual

\section{Producción Frigochaco}

\section{Cabezas de ganado faenado}

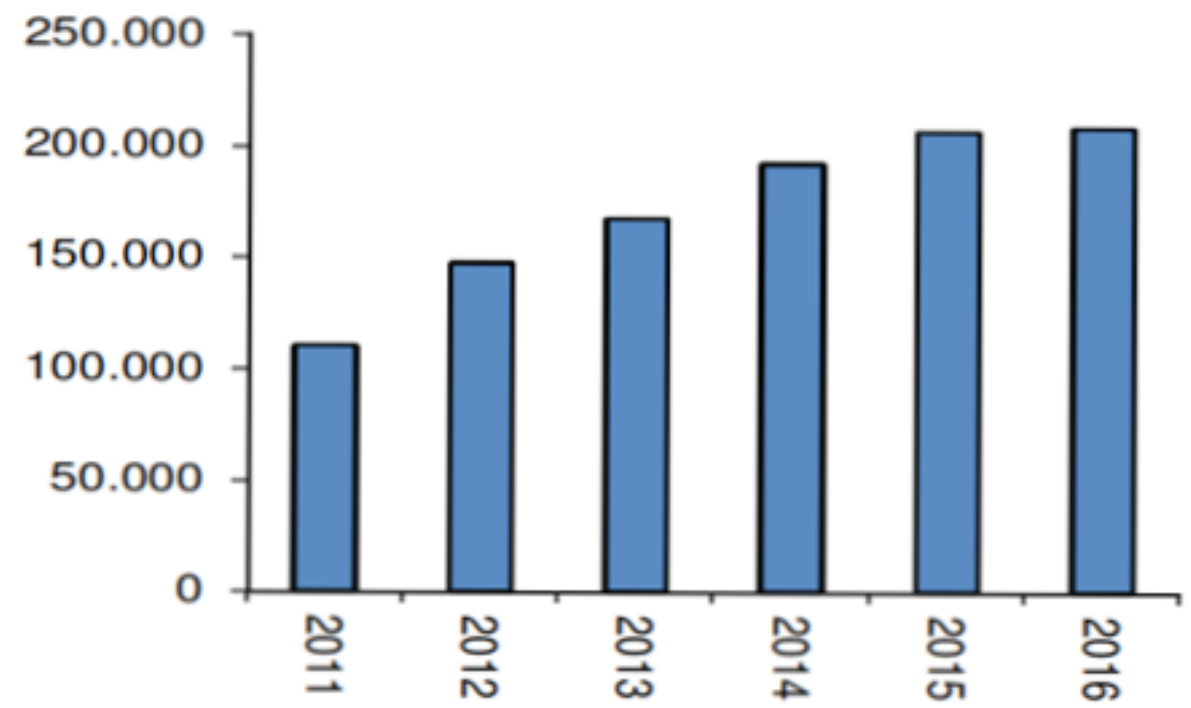

Fonte: Cooperativa Fernheim (2017).

\footnotetext{
${ }^{7}$ Informações obtidas no Setor de Informação e Documentação da Cooperativa Fernheim, em visita no dia 10 de setembro de 2017.

8 Idem.
} 
A comercialização de produtos lácteos, sob a marca COOP, tem uma posição relevante no mercado paraguaio. No período de 2011 a 2016, foram processados, em média, 25 milhões de litros de leite anuais. Os agricultores cooperados produzem, ainda, gergelim, amendoim, mamona, rícino, algodão e forrageira Gatton Panic, que são adquiridos e industrializados pela cooperativa (FELLER RATE, 2017).

Os oito mil habitantes da Colônia Fernheim distribuem-se em atividades de campo, comércios, frigoríficos, currais, indústrias e outros. O dispêndio de força de trabalho de diversos setores da produção produz o desenvolvimento eminentemente capitalista de produção, porque a Cooperativa, ao intervir na comercialização e na industrialização dos produtos, imprime a visibilidade do caráter capitalista no trabalho familiar ou comunitário do campo. Acresce-se que a formação de capital, os empréstimos bancários, a comercialização nacional e internacional, além do assalariamento dos trabalhadores nas atividades rurais e urbanas, compõem o conjunto da produção do lucro e ocorrem de acordo com as leis da sociedade produtiva ou conforme as leis do mercado.

Dessa forma, a investigação sobre a produção de mercadorias liderada pela cooperativa revelou a sua origem e existência pelo dispêndio da força de trabalho assalariada ou familiar na sociedade de Fernheim, com liberdade regida por contratos. A estrutura do capitalismo vincula liberdade e contrato, conforme a opinião manifestada por lanni (1993, p. 69): "A sociedade civil ou burguesa articula os princípios de liberdade, igualdade e propriedade com o contrato, compreendendo mercado, a produção de mercadoria, lucro e mais-valia".

A cooperativa investiu capital para criar novas forças produtivas. As relações de produção e o desenvolvimento das forças produtivas manifestaram-se na Colônia Fernheim. Verificou-se ali o que ocorria em outros locais do desenvolvimento capitalista. No dizer do sociólogo: "A mesma dinâmica do capitalismo cria e recria as forças produtivas e as relações de produção, tanto nas colônias, nos países dependentes e associados, como nos próprios países dominantes, metropolitanos ou imperialistas" (IANNI, 1993, p. 54).

O que caracterizou o caráter peculiar da sociedade produtiva da Colônia Fernheim não foi somente o crescimento econômico, mas também a tentativa de associar as forças produtivas modernas de produção ao bem-estar social das pessoas: qualidade da saúde, educação e redução da pobreza. Trata-se de uma tarefa complexa, porque a qualidade de vida tem como condição o desenvolvimento econômico. Sachs (2004, p. 214) escreveu que "o desenvolvimento não se confunde com crescimento econômico, que constitui apenas sua condição necessária, porém não suficiente". Na esteira de Sachs, Avelar (2012, p. 02) enfatizou o desenvolvimento formado por "um conjunto de fatores que determina o desenvolvimento econômico e o social, que devem caminhar juntos a fim de evitar as desigualdades, que assolam os países em vias de desenvolvimento".

Aferiu-se, na cooperativa e na sociedade produtora de mercadorias da Colônia, um modelo de desenvolvimento sustentável, que ultrapassa, na medida do possível, uma sociedade marcada somente pelo mercado ou pela esfera meramente econômica. Os objetivos da cooperativa de tentar realizar ali um desenvolvimento social estão postos. Parte-se da questão: o modo de produzir capitalista tem condições de realizar um desenvolvimento sustentável, visto que o fundamento é produzir sempre maior lucro? A questão é polêmica, mas considere-se que uma produção capitalista, além de utilizar o assalariamento do trabalhador e organizar a produção de mais-valia, propõe, também, "a transformação do produto em mercadoria e a do ser humano em produtor de mercadorias" (MARX, 1980, p. 87), com a finalidade de uma reprodução ampliada do capital. 
O fato de homens livres em Fernheim trabalharem com meios de produção próprios e empregarem "suas múltiplas forças individuais de trabalho, conscientemiente, como força de trabalho social" não se qualificam como um recuo à época da reprodução simples ou como oposição à sociedade capitalista, como querem fazer crer alguns autores. Da mesma forma não faz sentido a atribuição errônea de retrocesso à reprodução simples pelo fato de que os habitantes de Fernheim utilizam o termo comunidade ao lugar onde vivem. Em termos científicos, as comunidades entraram em dissolução com o fim da reprodução simples e passaram a constituir-se em sociedades produtoras de mercadorias.

A denominação de comunidade tem referência ao sistema feudal de produção; na sociedade produtora de mercadorias, a comunidade se transformou em sociedade civil. Entretanto, em Fernheim e em muitas regiões do Brasil, o termo comunidade permanece e, neste estudo, foi respeitado. Pertencer à comunidade menonita é visto como peculiaridade especial em tentar realizar um desenvolvimento social, na junção da Cooperativa com a Associação Civil. Os menonitas se autodenominam membros da comunidade e a vinculam aos princípios cristãos mantidos respeitosamente pela Associação Civil, uma instituição criada na Colônia com o objetivo de preservar os costumes e a religiosidade da população.

O aspecto econômico refere-se em grande parte às atividades da cooperativa; o social, entendido como saúde, educação, cultura, preservação de valores éticos e religiosos, cabe essencialmente à Associação Civil.

\subsection{A Associação Civil Fernheim}

A mediação que a cooperativa exerce entre a produção, a industrialização e a exportação de produtos articulam-se, também, com a Associação Civil de Filadélfia.

O depoimento de um morador de Fernheim referiu-se à criação da Associação, cuja finalidade é "dar assistência social, atendimento escolar e hospitalar aos menonitas", repetindo o que está, como missão, no seu Estatuto. Ela é responsável também pela manutenção das estradas, o seguro de carros e serviços de correio. O depoente concluiu: "Tudo é mais fácil agora".

Enquanto a Cooperativa cuida da parte econômica, a Associação é responsável pelas instituições sociais. Administra as "preocupações culturais, escolares e sociais da colônia. Os objetivos, a solução financeira e as questões administrativas estão assegurados pelo Código Civil, formalizados e aprovados pelo governo paraguaio". A ela pertencem "o hospital, as escolas, o lar de idosos, o Serviço Social, o Lar do Grupo, a oficina e o dormitório Kleefeld, o serviço de segurança e a construção de estradas" (MÜHLAN, 2014, p. 59).

A Associação Civil garante os princípios menonitas e os direitos individuais que se submetem aos interesses e às aspirações da comunidade. Ela foi legalizada em 1994. Em depoimento, o colaborador afirmou que "uma extrema necessidade durante os tempos difíceis da colônia levou os menonitas a criarem a Associação por meio de uma união solidária". Também em depoimento, o colaborador destacou: "As organizações estão interligadas, os membros da Cooperativa contribuem com uma taxa. Os serviços prestados pela Associação são direcionados para a melhoria e o bem-estar dos menonitas". Conforme o Estatuto, "a Associação é sustentada por um sistema de contribuição financeira, ligado à Cooperativa Fernheim".

De modo geral, os habitantes apontaram a Associação Civil para o enfoque do bem-estar social dos cooperados, de responsabilidade de todos os cooperados. O sistema adotado para 
se tornar sócio da Cooperativa Fernheim é o mesmo da admissão à Associação e os associados passam pelo mesmo processo de inserção. "Atualmente, quem é membro da cooperativa também é membro da Associação", afirma Mühlan (2014, p. 55).

A instituição é considerada como condição sine qua non para a perpetuação e difusão dos valores culturais, linguísticos e religiosos dos menonitas ${ }^{9}$.

Entre as ações que priorizam o bem-estar social, Pettinger (2015) destacou o sistema de saúde, ações destinadas ao atendimento das pessoas idosas, como a oportunidade de adquirir uma casa em terreno disponibilizado pela Associação e a educação escolar em idioma alemão e em espanhol. O Estatuto determinou que todas as crianças tenham aulas ministradas em alemão até a sétima série, além de falarem o dialeto plattdeutsch ("dialeto baixo-alemão"), originário do Norte da Alemanha, assim como também dominarem o espanhol.

Entre os serviços oferecidos pela Associação, houve destaque para três grandes áreas: educação, saúde e trabalho social. Especificamente na área da saúde, um depoente afirmou que "o hospital Filadélfia oferece serviços variados aos membros da Associação, como consultas, exames, tomografias". Há ainda atendimentos complementares e deslocamento em ambulâncias. Todos os serviços oferecidos pela Associação são pautados nos valores de solidariedade e cooperação entre os associados.

O importante a destacar é o seguinte: a peculiaridade do desenvolvimento, operada pela Cooperativa Fernheim, investigada neste artigo, proporcionou à Associação Civil concretizar as dimensões sociais, ambientais e culturais do desenvolvimento sustentável. O princípio encontra-se em Lima Filho (2010, p. 141), que afirma: "Só há desenvolvimento se o crescimento econômico for capaz de promover seu desenvolvimento sustentável". Esta é a função da Associação Civil.

\subsection{A escassez de água na Colônia Menonita}

Para sanar as dificuldades relacionadas à água - falta de chuvas e água salobra no subsolo -, os menonitas implantaram uma técnica, criada em Israel: canais ao longo das extensões de terras planas, visando ao acúmulo de água de uma bacia hidrográfica. Conseguiram, com esta técnica, abastecer uma sociedade que necessita diariamente de muita água. O sistema possui três componentes: uma área de coleta da chuva, um sistema de transporte (water distribution system) e uma área de armazenamento (storage area).

No Chaco Paraguaio, as áreas de baixa topografia utilizadas para armazenamento de águas pluviais são denominadas tajamares. Eles são construídos em áreas de solos argilosos com pelo menos três metros de profundidade. São acompanhados por canais de distribuição que transportam água da área de armazenamento para as áreas de uso. As áreas de coleta e de armazenamento são vedadas para evitar a contaminação por animais. A água da coleta corre até o tanque de armazenamento e, de lá, é transportada por uma bomba, cuja energia era gerada por moinho de vento. Atualmente, existe o abastecimento da energia elétrica vinda da Itaipu Nacional.

Na tentativa de atender à demanda de água potável, para uso industrial e agrícola, algumas técnicas sustentáveis foram adotadas também pela Cooperativa Fernheim, tais como a utilização de diques, poços artesianos e cisternas.

\footnotetext{
${ }^{9}$ Informações obtidas no Estatuto da Associação Civil.
} 
Larroza Cristaldo (2002, p. 75) destacou que, para assegurar o abastecimento de água potável na região do Chaco Central, construíram-se "reservatórios de infiltração (tajamares) nos extensos paleocanais do Chaco Central". Ao comentar sobre as dificuldades encontradas pelos menonitas no Chaco Central, um funcionário do setor informou:

A água foi a grande dificuldade encontrada na Colônia Fernheim tanto para consumo próprio quanto para manutenção da agropecuária. São poucos os rios de água doce. Em sua maioria, a água é salgada. Mas estamos fazendo as adaptações por meio de "tajamares" e "algibes".

Para a extração de água através de poços, é necessário realizar uma perfuração de 6 metros e, na maioria dos casos, a água é salobra. Este é um grande problema para os moradores e, por isso, é muito comum encontrarmos cisternas nas casas da região, para aproveitamento das águas das chuvas.

Por ser uma região semiárida, o Chaco Paraguaio apresenta um deficit hídrico no solo na maior parte do ano. No que diz respeito à Colônia Filadélfia, o investimento em tecnologia tem contribuído para a permanência dos menonitas na região, bem como tem permitido uma gestão integrada dos recursos hídricos, cujo manejo tem atendido quase à totalidade da população. Neste processo, a cooperação, a solidariedade e a laboriosidade foram fatores apontados como determinantes para o bem comum da Colônia Fernheim. O espírito menonita - a cultura, moral, política, os valores, a religiosidade, os interesses, as vontades - é infinitamente concreto e se traduz, converte-se, em trabalho social.

\section{CONSIDERAÇÕES FINAIS}

O entendimento de que as atividades da cooperativa na sociedade produtora de Fernheim apresentam-se em formas de reprodução simples da comunidade ou até em resistência ao capitalismo foi ultrapassado neste estudo, com a investigação de que o desenvolvimento proporcionado pela cooperativa é uma forma de produção peculiar, específica, que manifesta no seu interior as leis gerais da sociedade capitalista.

A mediação exercida pela Cooperativa Fernheim entre a produção, comercialização e industrialização de produtos apontou para o crescimento econômico, com investimentos voltados à melhoria das sementes, ao aumento da produção, à diminuição dos gastos e à viabilização da industrialização. A cooperativa atua numa variedade de produtos e serviços, bem como apresenta uma considerável ampliação do número de associados e da renda local. A análise deste estudo centrou-se sobre a realidade que singularizou as atividades da cooperativa, desvelando os traços econômicos e culturais típicos do espaço regional. Revelou a formação histórica, específica e própria, um tanto diferenciada de outros processos de ocupação existentes. Evidenciou, não obstante, que a produção do campo e a atividade industrial constituíram-se, essencialmente, conforme as leis gerais da produção capitalista, mediante a caução da Cooperativa Fernheim. Sua peculiaridade não é intrínseca ao município de Fernheim ou ao Chaco Paraguaio. Não se limita à área produtiva; está, sim, determinada pelo mercado. O que singulariza a mediação exercida pela cooperativa no seio da sociedade é uma forma peculiar de realização do universal; é um espaço particular onde se manifestam as leis gerais da sociedade produtora de mercadorias. Logo, é um tipo singular da produção capitalista.

A organização do trabalho sempre esteve articulada com a produção mercantil. Houve sempre uma produção que buscou constantemente o mercado externo, desde o fornecimen- 
to de produtos aos soldados do exército em guerra no início da colonização, até a atualidade, quando há uma reprodução ampliada do capital com tecnologia moderna de produção e com exportação no mercado nacional e internacional.

O que ocorreu em Fernheim foi a subordinação gradativa do trabalho ao empreendimento econômico de produção no campo e na comercialização que predominou no conjunto agrícola. E não poderia deixar de ocorrer, porque se trata de desenvolvimento da sociedade produtora de mercadorias. Ianni (1993, p. 152) descreveu o movimento do capital no espaço rural, em termos resumidos: "É a tecnocracia que se expande no campo".

$\mathrm{Na}$ economia, dominou e predominou a Cooperativa e todas as suas atividades produtivas foram organizadas segundo as exigências da reprodução do capital agroindustrial, especializado na pecuária (carne, leite e derivados) e na produção de grãos e forrageiras. Pela mediação exercida pela Cooperativa, as instituições sociais mantiveram-se ativas e atuantes em diversos setores, favorecidas pelas condições materiais necessárias para a concretização das atividades sociais, culturais e religiosas, funções reservadas à Associação Civil. Esta expressa o objetivo de capacitar os habitantes da Colônia Fernheim a obterem qualidade de vida em termos de saúde, educação e assistência social. À Associação cabe a função social de dar assistência aos moradores étnicos, latinos e indígenas e de realizar o espírito menonita, corporificado nos costumes e valores da vida, a fim de que todos possam formar e transformar sua história.

A necessidade de valorizar e utilizar ilimitadamente todas as aquisições da tecnologia na economia e na vida social ligou-se àquela essencialidade religiosa que permanece ativa entre os menonitas. Os depoimentos demonstraram a criação de campo de forças humano-sociais, capaz de determinar a unidade dos habitantes da Colônia Fernheim. E o espírito coletivo, de que todos falam, traduz-se na dignidade do trabalho social.

A Cooperativa Fernheim, preocupada com o desenvolvimento econômico, fez um esforço em alterar sua prática interna, articulando-se à Associação Civil; neste momento, também alterou a realidade da Colônia Fernheim. Por isso, foi investigada neste estudo no exercício de uma mediação: ela se justificou por sua razão de ser nos efeitos que se prolongaram para além dela, projetando-se em direção ao crescimento econômico ampliado e, aliada à Associação Civil, a uma tentativa possível de desenvolvimento social, cultural e religioso dos cidadãos da Colônia.

\section{REFERÊNCIAS}

AVELAR, A. S. História, tempo presente e testemunho: ainda em torno dos limites da representação. Revista Marcanan, Rio de Janeiro, v. 8, n. 8, p. 29-58, 2012.

BARDIN, L. Análise de conteúdo. Lisboa: Edições 70, 2004.

CHAUÍ, M. Os trabalhos da memória. In: BOSI, E. Memória e sociedade: lembrança de velhos. 16. ed. [S.I.: s.n.], 2010.

COOPERATIVA FERNHEIM. Setor de Informação e Documentação de Fernheim. Arquivo Acta de Evaluación de ofertas. Visita em 10 set. 2017.

COOPERATIVA FERnHEIM. Asociación de Colonias Mennonitas del Paraguay (folheto). Visita em 10 jul. 2017.

COOPERATIVA FERNHEIM. Disponível em: https://www.fernheim.com.py/en/. Acesso em: 10 jul. 2017. 
FELLER RATE. Fernheim Ltda. Colonizadora Multiactiva. Informe de Calificación, maio 2017. Disponível em: http://www.feller-rate.com.py/gp/informes/fernheimcol1706.pdf. Acesso em: 16 set. 2017.

IANNI, O. A sociedade global. Rio de Janeiro: Civilização Brasileira, 1993. 228 p.

LARROZA CRISTALDO, F. A. Exploração e aproveitamento dos recursos hídricos do Chaco Central Paraguaio. 2002. $161 \mathrm{f}$. Tese (Doutorado em Recursos Minerais e Hidrogeologia) - Instituto de Geociências, Universidade de São Paulo, São Paulo, 2002.

LIMA FILHO, S. C. Capital social e desenvolvimento local: a experiência de Campo do Brito (SE). 2010. 141 f. Dissertação (Mestrado em Economia) - Universidade Federal de Sergipe, São Cristóvão, 2010.

MARX, K. O capital. Rio de Janeiro: Civilização Brasileira, 1980.

MÜHLAN, T. Menonita alemão. Estudo da forma linguística e interação verbal em uma colônia religiosa no Paraguai. 2014. 327 f. Tese (Doutorado)- Universidade de Würzburg, Alemanha, 2014.

PARAGUAY. Ley n. 438/94. De Cooperativas. Disponível em: http://www.oas.org/juridico/spanish/ mesicic3_pry_ley438.pdf. Acesso em: 12 out. 2017.

PARAGUAY. Ley n. 514/21, de 26 de julio de 1921 Por la cual se acuerdan derechos y privilegios a los miembros de la comunidad mennonita que lleguen al país. Disponível em: https://escritosdederecho. blogspot.com/2013/05/por-la-cual-se-acuerdan-derechos-y.html. Acesso em: 13 jan. 2020.

PETTINGER, K. Viagem ao Chaco Paraguaio. Revista Agraria, Cascavel, PR, v. 3, n. 3, p. 18-20, 2015.

REYES, P. C. P. A Cooperativa Fernheim na Região do Chaco Paraguaio. 2009. 187 p. Dissertação (Mestrado em Desenvolvimento Regional) - Fundação Universidade Regional de Blumenau, Blumenau, SC, 2009.

SACHS, Ignacy. Caminhos De Um Desenvolvimento Sustentável. Rev. Ambiente e Sociedade. v. 7, n. 2, p. 214- 215, jul./dez. 2004. Disponível em: http://www.scielo.br/pdf/asoc/v7n2/24699.pdf. Acesso em: 11 set. 2017.

TORRACA, M. M. E. Imigração e colonização menonita no processo de legitimação do Chaco Paraguaio (1921-1935). 2006. 154 f. Dissertação (Mestrado em História)- Programa de Pós-Graduação em História, Universidade Federal da Grande Dourados, Dourados, MS, 2006.

WARKENTIN, Abe. Convidados e estrangeiros. Steinbach: O Posto Menonita, 1987.

\section{Sobre os autores:}

Odemir Coelho da Costa: Mestre em Meio Ambiente e Desenvolvimento Regional pela Universidade Anhanguera-Uniderp. Graduado em Geografia(UFMS). Atua na Rede Estadual de Ensino de Mato Grosso do Sul. E-mail: cabelojeep@hotmail.com, Orcid: https://orcid.org/0000-0001-6315-0522

Sandino Hoff: Doutor em Filosofia e História da Educação pela Pontifícia Universidade Católica de São Paulo (PUC-SP). Mestre em Educação pela Universidade Federal de São Carlos (UFSCar). Professor pesquisador da Universidade Anhanguera-Uniderp. E-mail: sandino.hoff@terra.com.br, Orcid: https://orcid.org/0000-0002-1521-6061 